\title{
Review
}

\section{A Long Journey into Aging, Brain Aging, and Alzheimer's Disease Following the Oxidative Stress Tracks}

\author{
Patrizia Mecocci*, Virginia Boccardi, Roberta Cecchetti, Patrizia Bastiani, Michela Scamosci, \\ Carmelinda Ruggiero and Marta Baroni \\ Department of Medicine, Institute of Gerontology and Geriatrics, University of Perugia, Perugia, Italy
}

Accepted 28 November 2017

\begin{abstract}
The Editors of the Journal of Alzheimer's Disease invited Professor Patrizia Mecocci to contribute a review article focused on the importance and implications of her research on aging, brain aging, and senile dementias over the last years. This invitation was based on an assessment that she was one of the journal's top authors and a strong supporter of the concept that oxidative stress is a major contributor to several alterations observed in age-related conditions (sarcopenia, osteoporosis) and, more significantly, in brain aging suggesting a pivotal role in the pathogenesis and progression of one of the most dramatic age-related diseases, Alzheimer's disease (AD). Her first pioneering research was on the discovery of high level of 8-hydroxy-2'-deoxyguanosine (OH8dG), a marker of oxidation in nucleic acids, in mitochondrial DNA isolated from cerebral cortex. This molecule increases progressively with aging and more in $\mathrm{AD}$ brain, supporting the hypothesis that oxidative stress, a condition of unbalance between the production of reactive oxygen species and antioxidants, gives a strong contribution to the high incidence of $\mathrm{AD}$ in old age subjects. OH8dG also increases in peripheral lymphocyte from $\mathrm{AD}$ subjects, suggesting that $\mathrm{AD}$ is not only a cerebral but also a systemic disease. The role of antioxidants, particularly vitamin $\mathrm{E}$ and zinc, were also studied in longevity and in cognitive decline and dementia. This review shows the main findings from Mecocci's laboratory related to oxidative stress in aging, brain aging, and $\mathrm{AD}$ and discusses the importance and implications of some of the major achievements in this field of research.
\end{abstract}

Keywords: Aging, Alzheimer's disease, antioxidant, brain aging, dementia, mitochondria, oxidative stress, vitamin E

\section{INTRODUCTION}

At the beginning of the 20th century, Alois Alzheimer first reported a case of a young patient with dementia whose brain contained characteristic histopathologic features defined as tangles and plaques [1]. The medical community has assimilated these observations and a diagnostic eponym, Alzheimer's disease (AD), has been assigned to such a condition [2]. For many years, memory loss and

\footnotetext{
*Correspondence to: Patrizia Mecocci, MD, PhD, Department of Medicine, Institute of Gerontology and Geriatrics, University of Perugia, Piazzale Gambuli 1, 06132 Perugia, Italy. Tel.: +39 0755783270; E-mail: patrizia.mecocci@unipg.it.
}

other cognitive deficits in the elderly have been considered as the result of the aging process and therefore called "senile dementia," whose prevalence and incidence increases exponentially with population aging. Expanding the definition of $\mathrm{AD}$ with the inclusion of those with senile dementia swelled the ranks of those diagnosed to such an extent that caused some to claim an "Alzheimerization" of dementia [3]. Nowadays, $\mathrm{AD}$ is the most diagnosed type of dementia representing a national health priority. For a long time, amyloid- $\beta(\mathrm{A} \beta)$ plaques and neurofibrillary tangles (NFTs) have been considered unquestionably the main cause of $\mathrm{AD}$ pathogenesis, but many other theories have been proposed, including 
oxidative stress and neuroinflammation, to explain a still unknown disease.

\section{THE AMYLOID CASCADE AND THE TAUOPATHY HYPOTHESES}

For many years, the amyloid cascade hypothesis has dominated $\mathrm{AD}$ thinking, modeling, and therapeutic approach. Amyloid proteins are beta-sheet proteins that can easily aggregate. $A \beta$ is a proteolytic degradation product of a larger molecule called amyloid- $\beta$ protein precursor (A $\beta P P$ ). Proteolysis by $\alpha$-secretase can occur 83 amino acids from the A $\beta P P$ intracellular carboxyl terminal. Alternatively, proteolysis by the enzyme $\beta$-secretase (BACE) cut 99 amino acids upstream of the A $\beta P P$ carboxyl end. An enzyme complex, $\gamma$-secretase, further processes the remaining carboxyl end of $\alpha$-secretase or $\beta$-secretase digested A $\beta P P$. This complex consists of the proteins presenilin 1, presenilin 2, nicastrin, APH-1, and PEN2 [4]. $\gamma$-secretase proteolysis does not uniformly occur at a single amino acid, although proteolysis either 57, 59, or 61 amino acids up from the A $\beta P P$ carboxyl terminus is most common. The 40-42 (although it can be 38-43) amino acid segment, directly created by $\beta$ - and $\gamma$-secretase proteolysis, is the $A \beta$ peptide. The amyloid cascade hypothesis postulates an overproduction of $A \beta$, which leads to neuronal dysfunction and apoptosis causing AD clinical manifestations [5]. According to this hypothesis, amyloid accumulation represents the "upstream" event in $\mathrm{AD}$ pathogenesis. This point of view has been overcome by the possibility that soluble $A \beta$ oligomers, more than mature amyloid plaques, are the key toxic moieties [6-8]. In fact, it has been demonstrated that amyloid oligomers may access intracellular organelles, including mitochondria, and compromise their function [9]. Amyloid deposition causes local inflammatory and immunologic alterations for a direct neurotoxicity with microglial recruitment and astrocyte activation. It is also associated with the release of cytokines, nitric oxide, and other radical species that can promote neuroinflammation and neurodegeneration. In addition to the amyloid cascade, intracellular NFTs are found in AD brain. They consist of hyperphosphorylated tau protein. Tau phosphorylation is regulated by a series of serine-threonine kinases [10], and tau protein interacts with microtubules of the cytoskeleton leading to the formation of NFTs. The interaction with cytoskeleton causes the destabilization of microtubules and consequently of intracellular trafficking of vesicles and organelles. Interestingly, NFTs correlate more closely with the severity of dementia than plaque counts [11-13]. The association of tangles with a variety of brain damage supports the "tauopathy" concept of neurodegeneration [14], although tauopathy as a primary cause of neurodegenerative diseases is currently demonstrable only in a subgroup of familial frontotemporal dementia. However, the recent failures of drugs targeting amyloid pathways have raised questions not only about this approach but also on the validity of the amyloid cascade hypothesis itself.

\section{OXIDATIVE STRESS AND DEMENTIA}

Oxidative stress is a condition where reactive oxygen species (ROS) production exceeds the cellular antioxidant defense system. In the cell, the main protective system is represented by the antioxidant enzymes, such as superoxide dismutase (SOD), glutathione peroxidase (GPX), glutaredoxins, thioredoxins, and catalase, in addition to non-enzymatic antioxidant factors, such as vitamin $\mathrm{E}$, vitamin $\mathrm{C}$, vitamin $\mathrm{A}$, uric acid, and carotenoids.

The brain is highly susceptible to an oxidative imbalance due to its high-energy demand, high oxygen consumption, an abundance of easily peroxidable polyunsaturated fatty acids, high level of potent ROS catalyst iron, and a relative paucity of antioxidant enzymes, this latter more evident in AD brain [15]. Oxidative stress causes damage by lipid peroxidation of membranes, such as plasma and mitochondrial membranes, or oxidation of structural and enzymatic proteins, with irreversible modification of protein tertiary structure and function, and of nucleic acids. Furthermore, $A \beta$ oligomers can insert into membrane bilayers leading to ROS production, followed by intracellular protein and nucleic acids oxidation.

Among products of lipid peroxidation, 4-hydroxy2-trans-nonenal (HNE) is highly reactive and primarily produced in the brain via lipid peroxidation of arachidonic acid, a highly abundant omega-6 polyunsaturated fatty acids (PUFA) component of neuronal membranes. HNE may modify the ATP synthase, the final step in the production of ATP from electron transport chain (ETC) inside mitochondria [16]. The ETC is a very efficient enzymatic system for energy production but, physiologically, a small amount of superoxide anion $\left(\mathrm{O}_{2}{ }^{\circ-}\right)$ is constantly produced due to electron leak, but antioxidants act to 
protect the cell from its deleterious action [17]. In fact, $\mathrm{O}_{2}{ }^{\circ-}$ can be converted into nonradical derivate such as hydrogen peroxide $\left(\mathrm{H}_{2} \mathrm{O}_{2}\right)$ either by a spontaneous dismutation reaction or catalyzed by the manganese superoxide dismutase that resides in the mitochondrial matrix [18]. $\mathrm{H}_{2} \mathrm{O}_{2}$ can be converted into hydroxyl radicals $\left({ }^{\circ} \mathrm{OH}\right)$ through the Fenton reaction. Similar to iron, copper also participates in the Fenton reaction, which exacerbates ROS production [19]. ${ }^{\circ} \mathrm{OH}$ can also be produced by a direct reaction of $\mathrm{O}_{2}{ }^{\circ-}$ with $\mathrm{H}_{2} \mathrm{O}_{2}$, a reaction known as the Haber-Weiss reaction.

Hence, mitochondria are prone to oxidative damage and particularly susceptible to ${ }^{\circ} \mathrm{OH}$-mediated oxidation, which plays a significant role in DNA oxidation.

To counteract an exaggerated production of ROS, mitochondria possess a very efficient antioxidant system, including glutathione peroxidase, catalase, and peroxiredoxin III, that can catalyze the electron transfer from NADPH to molecular oxygen and generate $\mathrm{O}_{2}{ }^{\circ-}$ [20]. Mitochondrial DNA (mtDNA) is particularly susceptible to oxidative damage because is localized near the ETC and is not surrounded by histones. All four bases (adenine, guanine, cytosine, and thymine) are susceptible to oxidative damage. The aging brain is characterized by an increased oxidative damage to mtDNA with the OH8dG formation, which is the most common marker of oxidative DNA damage. The simultaneous increased oxidation of mtDNA and deficiency of DNA repair could enhance the lesion to mitochondrial genome, potentially causing neuronal damages.

On this basis, it is reasonable that oxidatively mediated damage to biomolecules is extensively reported in $\mathrm{AD}$, suggesting that oxidative stress plays a critical role in the disease pathogenesis [21]. As the main source of ROS generation and a major target of oxidative damage, progressive impairment of mitochondria has been implicated in aging and AD [22]. The interaction between oxidative stress and mitochondrial dysfunction likely forms a vicious downward spiral that amplifies the alterations observed in AD.

\section{THE MITOCHONDRIAL CASCADE HYPOTHESIS}

Based on a large amount of data from in vitro and in vivo studies, in 2004 the mitochondrial cascade hypothesis was first proposed to explain $\mathrm{AD}$ pathogenesis [23]. It is generally accepted that mitochondrial function progressively declines along with age when compensation is no longer possible. In summary, the mitochondrial cascade hypothesis proposes that every single person has a genetically determined mitochondrial starting line, that together with environmental factors determine the age at which clinical disease may ensue. Thus, the "mitochondrial cascade hypothesis" places the mitochondrial dysfunction as the leading factor in the late-onset, non-autosomal dominant $\mathrm{AD}$ pathology cascade, underlying the individual genetic background able to regulate since birth its mitochondrial function and sustainability. For this reason, the rate at which age-related mitochondrial dysfunction proceeds differs among individuals. When the mitochondrial function declines and falls below a critical threshold, AD-typical dysfunction at the cellular level may ensue, including $A \beta$ production, tau phosphorylation, synaptic degeneration, and oxidative stress [24-26]. Some authors suggested that mtDNA could predict inheritance; accordingly, epidemiologic studies demonstrated that although both parents may contribute to an individual's AD risk [27], the maternal contribution is higher as compared with paternal [28], and maternal inheritance may specifically affect mid-life memory performance [29].

The fact that mtDNA polymorphisms influence $\mathrm{A} \beta$ production and plaque deposition in animal models expressing A $\beta P P$ transgene further support the mitochondrial cascade hypothesis [30]. Overall, it may be plausible that $A \beta P P$ and $A \beta$ homeostasis are finely regulated processes where bioenergetic metabolism plays a pivotal role.

\section{ALZHEIMER'S DISEASE: ONLY A NEURODEGENERATIVE DISEASE OR A SYSTEMIC DISEASE?}

The fact that some mitochondrial defects observed in AD patients are not brain-limited, as shown by lower enzymatic activity, such as cytochrome oxidase, in mitochondria from peripheral cells (platelets and fibroblasts), strongly support the concept that $\mathrm{AD}$ is a systemic disease [31, 32].

In fact, many studies demonstrated that subjects affected by $\mathrm{AD}$ have systemic manifestations that accompany the central nervous system (CNS) dysfunction. The association of AD with some systemic manifestations suggests that it is a multifactorial disease affecting both the brain and the periphery, in which different causative pathways play/interplay 
significant roles. Many factors that could increase the risk of developing AD have been identified, such as diabetes mellitus, obesity, and physical inactivity. Growing evidence is showing that physical activity may have a direct positive impact on brain health, not only by the regulation of cardiovascular and metabolic profile [33]. In fact, on one hand, physical activity may modulate cardiovascular risk factors, such as diabetes, hypertension, and stroke, that could, in turn, promotes dementia [34-37]; on the other hand, physical activity per se can increase the level of the brain-derived neurotrophic factor (BDNF) and stimulate neurogenesis [38, 39]. Physical activity is associated with larger brain volume, and this relationship could be mediated not only by BDNF but also by other neurotrophic factors not identified yet. Recent data showed that serum levels of BDNF are positively correlated with hippocampal volume, and that exercise is able to increase hippocampal levels of BDNF in animal models [40-43].

Furthermore, AD subjects also exhibit reduced VO2 peak (independent of dementia severity or physical function decline) correlated with brain atrophy [44], and imaging studies show that decreased aerobic fitness is associated with hippocampal atrophy in early $\mathrm{AD}[45]$.

Experimental studies suggest that also insulin pathway draws a clear trajectory from the peripheral to the central nervous system such as insulin treatment seems to enhance performance in subjects with $\mathrm{AD}$. Insulin can cross the blood-brain barrier where it modulates several processes such as neurotransmission, cell survival, and amyloid trafficking [46, 47]. Cognitive decline and dementia are among the most common complications of diabetes mellitus (DM), while in turn, a rise in adiposity increases the incidence of DM. Insulin resistance (IR) links obesity, pre-diabetes, and diabetes, which leads to an increased risk of developing cognitive decline. Elevated adiposity precedes and accompanies DM and leads to IR, which in turn promotes hyperinsulinemia. Hyperinsulinemia, insulin resistance, and other related conditions such as hypertension, dyslipidemia, and sub-clinical inflammation are related to a higher risk of cognitive impairment and $\mathrm{AD}$ in diabetic patients.

In this context, inflammation plays certainly a role. Plasma cytokines are known to communicate with the brain, and circulating levels of peripheral cytokines have been shown to reflect cytokine levels in the brain. Some studies have also shown that interindividual variations in peripheral cytokines levels are associated with individual differences in brain structures [48].

Recent studies show that metabolic state may affect nuclear DNA and neuronal plasticity with the regulation of chromatin structure, in particular by inducing histone modifications. A connection has been found between cellular metabolism, and neuronal plasticity with the neuronal function of enzyme acetyl-CoA synthetase 2 (ACSS2) as a chromatinbound transcriptional coactivator that stimulates histone acetylation and gene expression. AcetylCoA metabolism is cell- and tissue-specific, and it is frequently dysregulated in malignant transformation. Optimal acetyltransferase activity requires an increased local acetyl-CoA to CoA ratio, which determines the catalytic activity and substrate specificity of histone acetyltransferases (HAT) enzymes. This finding suggests that histone acetylation can be controlled by changing levels of nuclear acetyl-CoA. Thus, chromatin-bound ACSS 2 could provide acetylCoA to fuel HAT activity locally, instantaneously recycling CoA and could also recapture acetate from deacetylation reactions. Recently, it has been showed that specific chromatin binding by ACSS2 plays a crucial role in upregulation of immediate early genes with key functions in neuronal plasticity and longterm memory consolidation [49-51].

\section{ALZHEIMER'S DISEASE AND AGING: AN INSEPARABLE DUO?}

Advancing age represents the strongest risk factor $\mathrm{AD}$, but whether $\mathrm{AD}$ is a part of aging or whether aging is part of $\mathrm{AD}$ is still under debate. Along with aging, the structure and function of the brain change. Neurons are lost in the substantia nigra, mesial temporal region, and hippocampus; at the same time, the amount of neuritic plaques and NFTs increase. Cellular senescence is one of the main contributing factors to age-associated brain tissue dysfunction and represents the core feature of the so-called age-related changes (ARCs), leading to an overall reduction in brain volume and weight and enlargement of cerebral ventricles. ARCs arise from intrinsic/programmed and extrinsic/stochastic causes affecting neuronal viability and vulnerability. Among intrinsic factors, telomere shortening in neural stem cell—engaged in supporting brain tissues-plays certainly a role. Neural stem cells, in the dentate gyrus of the hippocampus and the subventricular zone beneath the lateral ventricles, are likely "replacement parts" for 
damaged or dying neurons. The progressive loss of chromosome ends with each replication events leads to cellular apoptosis [52]. Their depletion over a lifetime may contribute to decline in brain structure and function [53]. In this context, oxidative stress increases while mitochondrial energy production decreases along with cellular aging. In this view, considering the fundamental role of mitochondria in cellular bioenergetics, the decline in mitochondrial function represents probably the pivotal factor of cell aging.

\section{STUDIES ON THE ROLE OF OXIDATIVE STRESS IN AGING AND AGE-RELATED DISEASES FROM OUR RESEARCH LABORATORY}

The role of oxidative stress in aging, with a particular focus on brain aging, and in dementia have been the main topic of our research group since the $1990 \mathrm{~s}$. We developed different techniques to measure markers of oxidative stress in tissues of aged subjects, including centenarians, and in subjects suffering from cognitive impairment or dementia and then applied our methodologies in epidemiological studies.

\section{OXIDATIVE STRESS IN BRAIN AGING AND DEMENTIA}

\section{Oxidative stress in the brain}

In 1993, in collaboration with Prof. M. Flint Beal at the Harvard Medical School, oxidized nucleoside 8-hydroxy-2'-deoxyguanosine (OH8dG) was measured in nuclear (nDNA) and in mtDNA isolated from three regions of cerebral cortex and from cerebellum of humans aged 42 to 97 years. The amount of OH8dG increased progressively with age in both nDNA and mtDNA; however, the rate of increase was much greater in mtDNA. In fact, there was a significant 10 -fold increase for $\mathrm{OH} 8 \mathrm{dG}$ in mtDNA as compared with nDNA in the entire group of samples, and a 15-fold significant increase in those older than 70 years. These results showed for the first time that there is a progressive agerelated accumulation of oxidative damage to DNA in the human brain and that mtDNA is preferentially affected [54]. We hypothesized that such a damage contributed to the age-dependent increase in the incidence of neurodegenerative diseases. In fact, when we measured $\mathrm{OH} 8 \mathrm{dG}$ in the brain of subjects with $\mathrm{AD}$, we found a significant threefold increase for OH8dG in mtDNA in the parietal cortex of $\mathrm{AD}$ compared with controls. In the entire group of samples, there was a small significant increase in oxidative damage to nDNA and a highly significant threefold increase in oxidative damage to mtDNA in AD compared with age-matched controls. These results confirmed that mitochondrial DNA is particularly sensitive to oxidative damage, and showed that there is increased oxidative damage to DNA in $\mathrm{AD}$, which contributes to the neurodegenerative process [55].

To better identify the oxidative stress damage in the brain, the OH8dG and levels of mitochondrial DNA 4977 bp depletion (mtDNA ${ }^{4977}$ ) were determined from two brain areas of healthy subjects and $\mathrm{AD}$ patients. Postmortem brain tissue specimens were obtained from frontal and parietal cortices of six healthy subjects and seven patients affected by AD. The mean values either of mtDNA ${ }^{4977}$ and $\mathrm{OH} 8 \mathrm{dG}$ levels did not show significant differences between frontal and parietal areas in healthy or in the $\mathrm{AD}$ group. On the other hand, when controls and $\mathrm{AD}$ subjects were compared, the $\mathrm{OH} 8 \mathrm{dG}$ level in the $\mathrm{AD}$ patients was six- to eightfold higher than in healthy subjects, whereas mtDNA ${ }^{4977}$ percentage in the $\mathrm{AD}$ patients was about threefold lower than in the controls. A positive correlation between the agerelated increases of mtDNA 4977 and of OH8dG levels was found in the brain of healthy individuals. On the contrary, in both brain areas of AD patients, mtDNA $^{4977}$ levels were very low in the presence of high OH8dG amounts. We explained these results assuming that the increase of $\mathrm{OH} 8 \mathrm{dG}$ above a threshold level, as in $\mathrm{AD}$, implies consequences for mtDNA replication and neuronal cell survival [56].

To further support our observations on the role of oxidative stress in AD brain, we evaluated membrane fluidity, as a marker of peroxidation of membrane unsaturated fatty acids, in mitochondria extracted from brain tissue of normal aged and AD and evaluated also the effect of peroxidizing conditions on this biological parameter. Mitochondrial membrane fluidity was measured by means of fluorescence polarization of the lipophilic probe DPH. Mitochondrial membrane fluidity was significantly lower in $\mathrm{AD}$ compared to controls both when all samples were pooled as well as in different cerebral region with the exception of cerebellum. Under peroxidizing conditions $\left(\mathrm{FeCl}_{2}\right.$ and $\left.\mathrm{H}_{2} \mathrm{O}_{2}\right)$, membrane fluidity was further reduced in controls, particularly in mitochondria extracted from parietal and temporal areas. This 
did not happen when we tested mitochondria from AD brains, suggesting that, in this case, it was not possible to get further lipid peroxidation [57]. These observations suggest that a different susceptibility to oxidative damage exists in mitochondria of different brain areas, what was in agreement with our previous results concerning the evaluation of oxidative stress in mitochondrial DNA. In fact, when we related mitochondrial membrane fluidity with mtDNA damage, as measured by $\mathrm{OH} 8 \mathrm{dG}$ content, in $\mathrm{AD}$ brain we found a parallel increase of viscosity in mitochondrial membrane and of the amount of OH8dG in mtDNA, suggestive of a relationship between these biological markers of oxidative stress and so of a significant role of oxidative stress in $\mathrm{AD}$ pathogenesis [58].

The hypothetical dangerous effect of oxidative stress on mtDNA was also observed in diseases other than AD. In postmortem brain specimens of Huntington's disease, a twofold increase of OH8dG in mtDNA was found in the parietal and slightly less in the frontal cortex compared to controls, suggesting that oxidative damage to mtDNA plays an important role also in other neurodegenerative diseases [59].

\section{Oxidative stress in peripheral lymphocytes and in plasma molecules}

A significant amount of evidence supports the hypothesis that $\mathrm{AD}$ is not only a cerebral but also a systemic disease and that alterations observed in the brain could also be detected in the periphery. This issue has been recently brilliantly reviewed [60], summarizing several studies performed in the last years. From our side, we decided to evaluate if oxidative stress biomarkers could be detected in peripheral cells of subjects with $\mathrm{AD}$, and we choose lymphocytes as a model for this research.

In a first study, we measured OH8dG in nuclear DNA extracted from peripheral lymphocytes of old age subjects with AD and in healthy controls. We found a higher concentration of this biomarker of oxidative stress in $\mathrm{AD}$ and, what was of particular interest, the amount of $\mathrm{OH} 8 \mathrm{dG}$ increased along with age in controls, supporting again the role of aging as the main risk factor of those alterations leading to an increased risk of AD [61]. These data were later confirmed in another study where, in $\mathrm{AD}, \mathrm{OH} 8 \mathrm{dG}$ in nDNA of peripheral lymphocytes was inversely correlated with plasma concentration of several lipophilic antioxidants, such as lycopene, lutein, alpha- and beta-carotene. These findings suggest that lymphocyte OH8dG DNA content in patients with $\mathrm{AD}$ reflects a condition of increased oxidative stress possibly related to a poor antioxidant status [62].

Since mitochondria have shown such a fundamental role as a site of production of ROS as well as a target of their dangerous action, we set up a method to extract mitochondria from peripheral lymphocytes to examine more deeply and in detail any peculiar oxidative damage. In collaboration with Prof. Butterfield, at the University of Kentucky, measurements of biomarkers of oxidative stress on lipids and oxidative and nitrosative stress on proteins were performed in mitochondria extracted from lymphocytes of subjects suffering from AD and healthy age-matched controls. For the first time, increased levels of three biomarkers-namely, protein carbonyls, protein-bound $\mathrm{HNE}$, and protein-resident 3-nitrotyrosine-were detected in $\mathrm{AD}$, reinforcing the active role of oxidative damage in AD not only in the brain but also in peripheral cells [63]. This was true also in mild cognitive impairment (MCI), where all the three above-cited biomarkers were higher in lymphocyte mitochondria compared to controls. All biomarkers showed a significant negative correlation with the Mini-Mental State Examination (MMSE) score. Interestingly, they also negatively correlated with the antioxidants tocopherols and tocotrienols (vitamin E family). A further proteomic approach showed alterations in some proteins (thioredoxin-dependent peroxide reductase, myosin light polypeptide 6 , and ATP synthase subunit beta) that might be important in the progression and pathogenesis of $\mathrm{AD}$ [64].

More recently, we studied the activity and expression of aconitase $2\left(\mathrm{ACO}_{2}\right)$, a mitochondrial enzyme of the Krebs cycle, that is particularly sensitive to free radical damage. Mitochondria were extracted from lymphocytes of old age subjects with $\mathrm{AD}$ or MCI and in age-matched cognitively healthy controls. We found a reduced $\mathrm{ACO}_{2}$ activity in $\mathrm{AD}$ and MCI compared to controls. In the overall study population, $\mathrm{ACO}_{2}$ activity was significantly correlated with the plasma levels of the antioxidants vitamin $\mathrm{E}$, vitamin $\mathrm{A}$, vitamin $\mathrm{C}$, and uric acid as well as with the MMSE score. We hypothesized that the reduced activity was due to oxidative damage of the enzyme, linked to the paucity of antioxidants, but we also observed a reduced expression of $\mathrm{ACO}_{2}$ in $\mathrm{MCI}$ and $\mathrm{AD}$, that can contribute to a dysfunction in the Krebs cycle. Therefore, it is conceivable that the reduction of $\mathrm{ACO}_{2}$ activity in mild $\mathrm{AD}$, already present in the predementia phase (i.e., $\mathrm{MCI}$ ), might promote 
energy unbalance and foster the increase in oxidative and nitrosative stress, which then promotes $A \beta$ accumulation, synaptic dysfunction, and neuronal death [65].

Lack of antioxidants seems to have an important role in determining oxidative alterations in dementias. In another study conducted not only in AD but also in vascular dementia ( $\mathrm{VaD})$, we found a significant reduction in water-soluble (vitamin $\mathrm{C}$ and uric acid) and lipophilic (vitamin E, vitamin A, carotenoids including lutein, zeaxanthin, betacryptoxanthin, lycopene, alpha- and beta-carotene) antioxidant micronutrients in plasma of $\mathrm{AD}$ and $\mathrm{VaD}$ compared to cognitively healthy subjects. This poor antioxidant status was associated with higher levels of biomarkers of lipid peroxidation [malondialdehyde (MDA)] and of protein oxidation (immunoglobulin $\mathrm{G}$ levels of protein carbonyls and dityrosine) in patients compared to controls. Thus, independently of its nature (vascular or degenerative) dementia was associated with the depletion of a broad spectrum of antioxidant micronutrients and with increased protein oxidative modification [66]. All these results suggested a fundamental role of nutrition and of food or supplement antioxidants in the prevention of several age-related diseases that we started to investigate more in details in successive studies and reported in comprehensive reviews [67-69].

\section{OXIDATIVE STRESS IN MUSCLE AND IN BONE DISEASES}

Besides cerebral tissue, muscle is also mainly formed by post-mitotic cells, which are liable to accumulate oxidative damage over time, and both account for a large share of the body's total oxygen consumption at rest. So, we supposed that what we had observed in the brain could be also detectable in muscle and based on this assumption, we examined three well-established markers of oxidative damage to DNA (OH8dG), lipids (MDA), and proteins (carbonyl groups), respectively, in muscle biopsies obtained from healthy subjects aged 25 to 93 years. An increase of OH8dG and MDA was detectable after the age of sixty and also carbonyl groups increased, although not significantly [70].

In a further series of experiments in muscle specimens from vastus lateralis of young and old healthy subjects of both sexes, the increase of oxidative damage in DNA and lipids was confirmed in the elderly, more evident in men than in women, together with a reduction in the activities of the antioxidant enzymes catalase and glutathione transferase [71].

Taken together, these data strongly supported the impact of oxidative stress also in the aging of muscle and sarcopenia, that still represents a strong risk factor of weakness and falls in the elderly and, as a consequence, of severe disability.

We found alteration due to oxidative damage also in muscle specimens from subjects suffering from chronic fatigue syndrome (CFS), a still poorly understood condition characterized by long-lived, disabling fatigue associated with deficits in shortterm memory, impairments in concentration, sleep disturbances, and skeletal muscle pain. In particular, we detected a marked oxidative damage in DNA and lipids but also an increased activity of the antioxidant enzymes catalase, glutathione peroxidase, and transferase, with higher plasma levels of total glutathione in patients compared to age-matched controls. This suggests an increased production of free radicals in CFS that the organism tries to counteract increasing the endogenous antioxidant activities and justifying an organic origin of CFS, that is too often consider a psychological disease [72].

In old-age subjects, a pro-oxidant status was also observed in a common disease such as osteoporosis. In fact, in a population of postmenopausal women, living independently, in good health and nutritional status, and affected by mild or no disability, those who suffered from osteoporosis had consistently lower plasma levels of vitamin $\mathrm{C}$, vitamin $\mathrm{E}$, vitamin $\mathrm{A}$, and uric acid compared to controls. Despite this, none of the subjects belonging to the two groups had levels below the normal vitamin $\mathrm{C}$ and vitamin $\mathrm{E}$ ranges. The activities of antioxidant enzymes in plasma (SOD and GPX) and erythrocytes were significantly lower in osteoporotic than in controls. The study showed the negative effect of low levels of antioxidants in bone mass and fracture risk, as demonstrated in epidemiological studies. Of note, vitamin $\mathrm{C}$ is a cofactor in the maturation of collagen. We explained these observations supposing an inadequate antioxidant intake that can affect osteoclastogenesis [73].

\section{OXIDATIVE STRESS IN CEREBROVASCULAR DISEASES}

An increased production of free radicals has been constantly observed in the brain in both ischemic and hemorrhagic stroke. Therefore, it is conceivable that in these acute conditions a deficiency in antioxidants 
may reduce resistance against the damage, leading to a status of oxidative stress [74].

We investigate this hypothesis evaluating the antioxidant profile in plasma of subjects suffering from a stroke, in order also to establish the impact of the antioxidant status on the prognosis and to evaluate a potential effect of antioxidants in stroke therapy.

In subjects with cortical stroke, we found higher levels of lipid hydroperoxides (measured as cholesteryl ester hydroperoxides, $\mathrm{CEOOH}$ ), with a peak at day-five after the acute event, compared to subjects with lacunar infarcts. This was accompanied by reduced levels of the antioxidant vitamin $\mathrm{C}$, or ascorbic acid that did not differ significantly between groups. CEOOH levels correlated with severity of the stroke, as evaluated by the NIH stroke scale and the Glasgow coma scale, and with stroke volume and site-higher in total anterior than in posterior cerebral syndrome [75]. In a subsequent study, several plasma enzymatic (SOD, GPX, and erythrocyte SOD (eSOD) activities) and non-enzymatic (vitamins A, E, C and uric acid) antioxidants were serially measured in subjects suffering from acute ischemic stroke of recent onset on admission and at specific time points in the first week. Antioxidant levels in patients on admission were compared with those of age- and sex-matched controls. The mean antioxidant levels and activities in patients on admission were lower than those of controls with a gradual increase over time. Patients with the worst early outcome (death or functional decline) had higher vitamin A and uric acid plasma levels and lower vitamin $\mathrm{C}$ levels and eSOD activity than those who remained functionally stable, suggesting that the majority of antioxidants are reduced immediately after an acute ischemic stroke, possibly as a consequence of increased oxidative stress, and that a specific antioxidant profile is associated with a poor early outcome [76]. Also, other lipophilic antioxidants such as carotenoids were found significantly lower and MDA higher after stroke in the same population, with a lower amount of lutein in those with a poor early outcome [77].

All these observations suggested that vascular damage can be modulated by antioxidant status and this not only in ischemic but also in hemorrhagic stroke, where vitamin C plasma levels were significantly correlated with the severity of the neurological impairment, as assessed by the Glasgow Coma Scale and the NIH Stroke Scale, as well as with the major diameter of the lesion [78]. Vitamin C was also found lower in plasma of oldest-old subjects with hyperhomocysteinemia suffering from stroke [79] suggesting that this vitamin could have a significant effect in protecting against oxidative stress due to ischemic or hemorrhagic stroke. For this reason, we conducted a multicentric study named AVASAS (Aspirin versus Ascorbic acid plus Aspirin in Stroke) study to evaluate the effect of vitamin $\mathrm{C}$ added to standard therapy with aspirin regarding clinical outcomes and plasma biomarkers of oxidative stress. In the acute phase and along with time until the end of the three months of therapy, we found lower levels of 8,12-isoprostanes $\mathrm{F}_{2 \alpha}$-VI, a specific marker of lipid peroxidation, and higher levels of vitamin $\mathrm{C}$ in those treated with the association compared to aspirin alone, while the functional outcomes were similar between groups [80]. The relationship between high levels of oxidative damage biomarkers and low antioxidants in plasma was revealed also in studies on conditions at risk for both cerebrovascular and neurodegenerative diseases such as diabetes [81], atherosclerosis [82, 83], congestive heart failure [84], a definite risk for $A D$ in the elderly [85], suggesting that vascular risk factors can act as so through oxidative stress mechanisms particularly in the oldest-old [86-88], who appears a sub-group of population more sensitive than younger to oxidative stress [89]. The relationship between reduction of antioxidant defenses and aging seemed more and more intriguing. Therefore, the question was: if aging is the major risk factor for $\mathrm{AD}$ and antioxidants decrease with aging, could we modulate the risk for AD with antioxidants, like diet or supplementation? To answer this question, we decided to study a particular aged population: the centenarians.

\section{ANTIOXIDANTS IN CENTENARIANS}

Healthy centenarians can be considered a good example of "successful aging", and although genetic factors influence their longevity, environmental aspects are also of great importance and, among them, diet is probably one of the most influent. Since aging is associated with oxidative stress, and antioxidant defense systems were developed by the organism to guarantee its survival, we decided to evaluate the antioxidant status in centenarians to understand if this could influence such an extreme longevity. To this purpose, we measured a broad set of enzymatic (SOD, eSOD, and GPX activities) and non-enzymatic (vitamins A, C, E; carotenoids, and uric acid) antioxidants in plasma of a group of healthy centenarians comparing them with other three groups aged $<60$ years, 61-80 years, and $81-90$ years. The most striking 
findings were the highest levels of vitamin A and vitamin $\mathrm{E}$ in centenarians compared to all the other groups, that, instead, after exclusion of centenarians from regression analysis, showed a significant decrease of all non-enzymatic antioxidants and increase of plasma SOD and eSOD activities along with age [90]. So, the main characteristic of centenarians seemed to be the high levels of lipid soluble vitamins, $\mathrm{A}$ and $\mathrm{E}$, but when we analyzed more in details the characteristics of our centenarian population, that lived in different geographic areas of Italy, surprisingly we found that those living in Sardinia island-famous for being one of the regions in the world with the highest number of centenarians - had high plasma levels of uric acid but not high level of vitamin $\mathrm{A}$ and vitamin $\mathrm{E}$ as the centenarians from the other regions. Thus, probably in this particular group of Sardinian centenarians genetic, rather environmental factors, seem to play a significant role in longevity compared to other Italian populations [91]. This is a plausible explanation, considering that Sardinia has been quite isolated from the rest of Italy for a long time and its demographic characteristics are peculiar as, for example, the ratio between male and female centenarians, that is different from the rest of Italy [92].

\section{THE WAR AGAINST OXIDATIVE STRESS: ANTIOXIDANTS IN POPULATION STUDIES}

All the studies we performed in old age subjects with different type of chronic age-related diseases lead to the same conclusion: a status of poor antioxidant levels detected in plasma is associated with a higher risk to be affected, strongly supporting the idea that a good food intake of antioxidants results in a better health condition and protection from several diseases. If this is true, and probably obvious, in young population in order to prevent future diseases, and also in subjects definite as young-old (65-75 years of age), it is less evident if changing habits, including diet, in the old (75-84 years) and oldestold (over 85 years) populations can have benefit in terms of physical and mental health.

In a study on healthy elderly subjects who underwent a diet very rich in fruit and vegetables, compared to age-matched subjects with a poor intake of both, we found high levels of plasma lipophilic antioxidants in the first group, together with lower levels of the oxidative by-products MDA and protein carbonyls. These differences were maintained after age correction, suggesting that, no matter how old a subject is, a long-term balanced diet with high content of fruits and vegetables prevents, at least in part, the formation of oxidatively damaged molecules [93]. A further interventional study in old-age subjects who consumed a high rich diet of fruits and vegetables for almost one year, not only plasma antioxidants were higher and oxidative stress biomarkers lower compared to low-intake age-matched group, but they also showed, what is noteworthy, better cognitive functions as evaluated by a large neuropsychological battery [94]. Therefore, a good antioxidant status seems to be protective against cognitive decline and, in fact, in subjects with MCI, we detected a similar depletion of plasma antioxidant as in $\mathrm{AD}$ when compared with age-matched cognitively healthy controls. It was particularly interesting the observation that, although the non-enzymatic antioxidants were low, there was not a parallel induction of activity of antioxidant enzymes, such as SOD or GPX, not only in AD but also in MCI [95]. Hence, with MCI a condition at risk for conversion to $\mathrm{AD}$, a diet containing high levels of antioxidants may correct an antioxidant imbalance and prevent or delay a further deterioration toward dementia. Furthermore, measurements of peripheral markers of oxidative stress could be useful in detecting those subjects more responsive to a supplement of antioxidants, an aspect not properly explored in trials with, for example, vitamin $\mathrm{E}$ that failed to protect against $\mathrm{AD}[96,97]$. In fact, the effect of supplementation should be evaluated only in those lacking a specific micronutrient, an approach that should not be proposed indiscriminately. Since vitamin $\mathrm{E}$ was used in the treatment of $\mathrm{MCI}$ and of $\mathrm{AD}$, we decided to investigate more in detail its role in population studies. In fact, revising the few randomized clinical trials with vitamin $\mathrm{E}$, we found that only $\alpha$-tocopherol was used as treatment, while under the umbrella of the term vitamin E several other natural forms are present, namely $\alpha-, \beta-, \gamma-, \delta$-tocopherol and $\alpha-, \beta-, \gamma-, \delta$-tocotrienol. $\alpha$-Tocopherol is a prevalent form in the organism, but the other forms have unique antioxidant and anti-inflammatory properties that are also higher than $\alpha$-tocopherol in prevention and therapy of chronic diseases [98]. Thus, their role in cognitive impairment was worthy to be examined in depth.

To this purpose, we measured plasma levels of the eight vitamin $\mathrm{E}$ forms as well as of $\alpha$ tocopherylquinone, $\alpha \mathrm{TQ}$ (byproduct of oxidation of $\alpha$-tocopherol) and of 5-nitro- $\gamma$-tocopherol, $5 \mathrm{~N} \gamma \mathrm{T}$ 
(byproduct of nitrosative damage of $\gamma$-tocopherol), in a large number of free-living elderly (over 65) who participated in the Conselice study [99], a populationbased Italian study that evaluated the incidence of dementia after a four-year follow-up. The prevalence of dementia at baseline was highest among participants with higher concentrations of $\delta$-tocopherol and $\alpha \mathrm{TQ}$ while in the longitudinal analysis a lower risk of dementia was detected in those in the middle tertile of plasma $\gamma$-tocopherol at baseline [100]. So, in this old-age population, both prevalent and incident cognitive impairment was associated with plasma concentrations of non $\alpha$-tocopherol forms of vitamin $\mathrm{E}$, suggesting that dietary interventions, more than supplementation with $\alpha$-tocopherol, may affect the risk of cognitive impairment in the elderly.

The same set of molecules were measured in plasma of cognitively healthy subjects, older than eighty years, participating in the Kungsholmen study, a community-based study on aging and dementia based in a district of Stockholm. Plasma samples were collected at baseline and incidence of dementia evaluated after a six-year follow-up. After correction for several confounders, subjects with total tocopherols, total tocotrienols, and total vitamin E plasma levels in the highest tertile had a reduced risk of developing AD compared to those in the lowest tertile. When considering each form, the risk of incident $\mathrm{AD}$ was lower in subjects with levels of $\beta$-tocopherol in the highest tertile compared to the lowest, with a trend of protective effects for $\alpha$-tocopherol, $\alpha$-tocotrienol, and $\beta$-tocotrienol. Overall, this study suggests that low plasma levels of vitamin $\mathrm{E}$ in late life may be involved in the development of AD but that the protective activity seems to be related to the combination of different forms, that can be guaranteed by dietary intake, more than by supplementation with only $\alpha$-tocopherol [101].

We applied a similar study protocol also to a Finnish population from the Cardiovascular Risk Factors, Aging and Dementia (CAIDE) study, characterized by a longitudinal design with several follow-ups every five years, with the aim to detect the incidence of several chronic diseases in relationship with midlife risk factors. In a subsample of this population, we evaluated the eight forms of vitamin $\mathrm{E}$ as well as the biomarkers of their oxidative or nitrosative damage in collected plasma samples of subjects clinically re-evaluated after seven to ten years. The study revealed an association between higher serum levels of $\gamma$-tocopherol, $\beta$-tocotrienol, and total tocotrienols and reduced risk of dementia. Furthermore, an elevated index of vitamin $\mathrm{E}$ nitrosative damage, i.e., the $5 \mathrm{~N} \gamma \mathrm{T} / \gamma$-tocopherol ratio, indicating a consumption of $\gamma$-tocopherol in free radical reactions, was associated with an increased risk of cognitive impairment [102].

In a further study on subjects with MCI or $\mathrm{AD}$ enrolled, together with cognitively healthy agematched subjects, in the AddNeuroMed project, a multicenter European longitudinal study on the detection of biomarkers for $\mathrm{AD}$, measurement of the vitamin E molecules previously described, showed that high plasma levels of tocopherols and of tocotrienols are associated with reduced odds of MCI and $\mathrm{AD}$. In both groups, reduced levels of $\alpha$-tocopherol and $\gamma$-tocopherol, as compared to controls, were associated with increased indexes of their utilization due to reaction with free radicals, suggesting that vitamin $\mathrm{E}$ depletion could be due to its increased utilization in oxidative and nitrosative stress events [103]. In a sub-study on this population, plasma concentrations of all forms of vitamin $\mathrm{E}$ and of markers of their oxidative/nitrosative damage were combined with structural magnetic resonance imaging (MRI) measures to evaluate the accuracy in differentiating individuals with $\mathrm{AD}$ and $\mathrm{MCI}$ from cognitively intact control (CTL) subjects. The joint evaluation of MRI and plasma vitamin $\mathrm{E}$ measures enhanced the accuracy of differentiating individuals with $\mathrm{AD}$ and MCI from CTL subjects: $98.2 \%$ (sensitivity $98.8 \%$, specificity $97.7 \%$ ) for AD versus CTL, and $90.7 \%$ (sensitivity $91.8 \%$, specificity $89.5 \%$ ) for MCI versus CTL. This combination of measures also identified $85 \%$ of individuals with MCI who converted to clinical $\mathrm{AD}$ at follow-up after one year [104].

Also, in a functional neuroimaging study with ${ }^{18}$ F-FDG PET, which evaluates cerebral glucose utilization, performed in subjects with subjective cognitive impairment, MCI and mild AD, brain glucose metabolism progressively decreased bilaterally in posterior temporoparietal and cingulate cortices across the three groups and, interestingly, the extracellular SOD activity measured in plasma was positively correlated with glucose metabolism in a large area of the left temporal lobe. Extracellular SOD is mainly bound to the endothelial surface of the arterial wall, while a small amount is released into the plasma, being in equilibrium with the endothelial component. Several studies showed that extracellular SOD is involved in regulating cerebral flow by maintaining the balance between nitric oxide and superoxide in the sub-endothelial space. Therefore, reduced activ- 
ity, and probably amount, of this enzyme might contribute to the reduction of blood flow, and then metabolism, we observed in the brain [105].

In summary, most of the cross-sectional and longitudinal studies focused on oxidative stress in aging, brain aging, and dementia is quite concordant on its pivotal role as a cause of many structural and functional alterations in all these conditions, but, on the other hand, most of the clinical trials based on the use of antioxidants failed in finding beneficial effects. Why?

\section{COULD WE PREVENT COGNITIVE DECLINE AND OXIDATIVE STRESS DAMAGE WITH ANTIOXIDANTS AND/OR DIETARY HABITS?}

Much evidence has shown, along with time, the role of micronutrients in protecting against several diseases, in our case those associated with aging, but most of the interventional studies were not successful. Vitamin $E$ is paradigmatic to this purpose. After a great enthusiasm when vitamin E use was associated with a slower decline in $\mathrm{AD}$ [106], all the following studies failed in finding beneficial effects of vitamin E supplementation in AD and MCI. But many biases are present in most of them [107]. The first is the treatment with only $\alpha$-tocopherol, which at high dose reduces or blocks the absorption of all the other essential tocopherols and tocotrienols, probably causing a deleterious biochemical imbalance in the organism. Furthermore, there was not a baseline evaluation of vitamin E status, so it is conceivable that many subjects did not suffer from vitamin deficiency and they were over/useless-treated. This is not a trivial consideration since, for example, we know that, without a good level of vitamin $\mathrm{C}$, the increase in $\alpha$-tocopherol can modify the redox balance, with an increase in oxidized forms of $\alpha$-tocopherol that cannot be re-reduced by ascorbic acid. However, this is just an example of possible alteration we could cause without a profound knowledge of biochemical pathways. From this perspective, in a study conducted in a broad healthy community-dwelling old subjects, we found a progressive decline with age of another micronutrient, zinc ( $\mathrm{Zn})$, with the lowest levels in nonagenarians, who showed inadequate plasma levels in more than $60 \%$ [108]. Few weeks of supplementation increased $\mathrm{Zn}$ plasma levels in subjects with low but not in those with normal levels at baseline, suggesting that supplementation is beneficial mainly, or only, in the state of deficiency [109]. Therefore, if we want to treat patients with vitamins or other nutraceuticals, as frequently suggested also for cognitive impairment and $\mathrm{AD}$ [110], we need to know better their physiological actions and interactions, chemical properties and side effects. Every proposed nutraceutical must be studied as a new drug, passing through all phases of a clinical trial, with a rigorous flowchart.

However, it is also more probable that a wellbalanced diet is the most reasonable approach to guarantee the best strategy to maintain a good health status with all nutrients obtained at a more equilibrated concentration.

To this purpose, it is noteworthy that nutrition and lifestyle are the most important contributors to a long and healthy life also through telomere biology modulation. Telomeres are long sequences of nucleotides at the end of our chromosomes, forming with specific proteins complex, an "end caps" which preserve genome stability and lead a cell to divide correctly. Extremely short or dysfunctional telomeres can be repaired by the enzyme telomerase, that working as a reverse transcriptase, adds nucleotides at the end of each chromosome promoting its stability.

Lifestyle factors known to modulate aging and agerelated diseases might also affect telomerase activity [111]. Obesity, insulin resistance, and cardiovascular disease processes, which are related to oxidative stress and inflammation, have all been linked to alteration in telomere/telomerase system, which leads to cellular senescence [112]. Cellular senescence, the state of irreversible cell-cycle arrest, in turns contributes to age-related loss of tissue function and the production and secretion of reactive oxygen species as well as bioactive peptides collectively known as the senescence-associated secretory phenotype. Cellular senescence in the brain contributes to AD pathogenesis and may represent a link between the aging process and disease progression [113].

\section{CONCLUSIONS}

What is the leading factor in $\mathrm{AD}$ pathogenesis remains unknown and $A \beta$ deposition may be an expression of upstream alterations. Among them, oxidative stress has a crucial role, as summarized in Tables 1 and 2. Oxidative damage may impair the cells in their structure and function, being cause and effect of a mitochondrial reduced activity. The damage is not confined to the brain but also evident in peripheral cells and tissues. Thus we have 
of a famous song (not mentioning the end of the lyric, too pessimistic for any traveling researcher).

\author{
Well we know where we're going \\ But we don't know where we've been \\ And we know what we're knowing \\ But we can't say what we've seen \\ And we' re not little children \\ And we know what we want \\ And the future is certain \\ Give us time to work
}

Talking Heads

\section{ACKNOWLEDGMENTS}

We would like to thank Prof. Maria Cristina Polidori and Dr. Francesca Mangialasche for their long-lasting friendship and collaboration to produce many of the presented results.

Authors' disclosures available online (https:// www.j-alz.com/manuscript-disclosures/17-0732r1).

\section{REFERENCES}

[1] Alzheimer A, Stelzmann RA, Schnitzlein HN, Murtagh FR (1995) An English translation of Alzheimer's 1907 paper, "Uber eine eigenartige Erkankung der Hirnrinde". Clin Anat 8, 429-431.

[2] Kraepelin E (1910) Psychiatrie. Ein Lehrbuch fur Studierende und Artze. II. Band, Klinische Psychiatrie. Leipzig: Verlag Johann Ambrosius Barth, 5, 789-814.

[3] Royall D (2003) The "Alzheimerization" of dementia research. J Am Geriatr Soc 51, 277-278.

[4] Edbauer D, Winkler E, Regula JT, Pesold B, Steiner H, Haass C (2003) Reconstitution of gamma-secretase activity. Nat Cell Biol 5, 486-488.

[5] Cummings JL, Cole G (2002) Alzheimer disease. JAMA 287, 2335-2338.

[6] Lesné S, Kotilinek L (2005) Amyloid plaques and amyloid-beta oligomers: An ongoing debate. J Neurosci 25, 9319-9320.

[7] Lesné S, Koh MT, Kotilinek L, Kayed R, Glabe CG, Yang A, Gallagher M, Ashe KH (2006) A specific amyloid-beta protein assembly in the brain impairs memory. Nature $\mathbf{4 4 0}$, 352-357.

[8] Glabe CC (2005) Amyloid accumulation and pathogenesis of Alzheimer's disease: Significance of monomeric, oligomeric and fibrillar Abeta. Subcell Biochem 38, 167-177.

[9] Lustbader JW, Cirilli M, Lin C, Xu HW, Takuma K, Wang N, Caspersen C, Chen X, Pollak S, Chaney M, Trinchese F, Liu S, Gunn-Moore F, Lue LF, Walker DG, Kuppusamy P, Zewier ZL, Arancio O, Stern D, Yan SS, Wu H (2004) ABAD directly links Abeta to mitochondrial toxicity in Alzheimer's disease. Science 304, 448-452.
[10] Billingsley ML, Kincaid RL (1997) Regulated phosphorylation and dephosphorylation of tau protein: Effects on microtubule interaction, intracellular trafficking and neurodegeneration. Biochem J 323, 577-591.

[11] Berg L, McKeel DW Jr, Miller JP, Baty J, Morris JC (1993) Neuropathological indexes of Alzheimer's disease in demented and non demented persons aged 80 years and older. Arch Neurol 50, 349-358.

[12] Berg L, McKeel DW, Miller JP, Storandt M, Rubin EH, Morris JC, Baty J, Coats M, Norton J, Goate AM, Price JL, Gearing M, Mirra SS, Saunders AM (1998) Clinicopathologic studies in cognitively healthy aging and Alzheimer's disease: Relation of histologic markers to dementia severity, age, sex, and apolipoprotein E genotype. Arch Neurol 55, 326-335.

[13] Giannakopoulos P, Herrmann FR, Bussière T, Bouras C, Kövari E, Perl DP, Morrison JH, Gold G, Hof PR (2003) Tangle and neuron numbers, but not amyloid load, predict cognitive status in Alzheimer's disease. Neurology 60, 1495-1500.

[14] Lee VM, Goedert M, Trojanowski JQ (2001) Neurodegenerative tauopathies. Annu Rev Neurosci 24, 1121-1159.

[15] Kim TS, Pae CU, Yoon SJ, Jang WY, Lee NJ, Kim JJ, Lee SJ, Lee C, Paik IH, Lee CU (2006) Decreased plasma antioxidants in patients with Alzheimer's disease. Int $J$ Geriatr Psychiatry 21, 344-348.

[16] Perluigi M, Sultana R, Cenini G, Di Domenico F, Memo M, Pierce WM, Coccia R, Butterfield DA (2009) Redox proteomics identification of 4-hydroxynonenal-modified brain proteins in Alzheimer's disease: Role of lipid peroxidation in Alzheimer's disease pathogenesis. Proteomics Clin Appl 3, 682-693.

[17] Valko M, Leibfritz D, Moncol J, Cronin MT, Mazur M, Telser J (2007) Free radicals and antioxidants in normal physiological functions and human disease. Int J Biochem Cell Biol 39, 44-84.

[18] Hamanaka RB, Chandel NS (2010) Mitochondrial reactive oxygen species regulate cellular signaling and dictate biological outcomes. Trends Biochem Sci 35, 505513.

[19] Sayre LM, Perry G, Harris PL, Liu Y, Schubert KA, Smith MA (2000) In situ oxidative catalysis by neurofibrillary tangles and senile plaques in Alzheimer's disease: A central role for bound transition metals. J Neurochem $\mathbf{7 4}$, 270-279.

[20] Block ML (2008) NADPH oxidase as a therapeutic target in Alzheimer's disease. BMC Neurosci Suppl 2, S8.

[21] Nunomura A, Perry G, Aliev G, Hirai K, Takeda A, Balraj EK, Jones PK, Ghanbari H, Wataya T, Shimohama S, Chiba S, Atwood CS, Petersen RB, Smith MA (2001) Oxidative damage is the earliest event in Alzheimer disease. J Neuropathol Exp Neurol 60, 759-767.

[22] Ansari MA, Scheff SW (2010) Oxidative stress in the progression of Alzheimer disease in the frontal cortex. J Neuropathol Exp Neurol 69, 155-167.

[23] Swerdlow RH, Khan SM (2004) A "mitochondrial cascade hypothesis" for sporadic Alzheimer's disease. Med Hypotheses 63, 8-20.

[24] Swerdlow RH (2012) Alzheimer's disease pathologic cascades: Who comes first, what drives what. Neurotox Res 22, 182-194.

[25] Swerdlow RH (2011) Brain aging, Alzheimer's disease, and mitochondria. Biochim Biophys Acta 1812, 16301639. 
[26] Simon DK, Chu CT, Swerdlow RH (2012) Mitochondria and Parkinson's disease. Parkinsons Dis 2011, 261-791.

[27] Katzman R (1986) Alzheimer's disease. NEngl J Med 314, 964-973.

[28] Edland SD, Silverman JM, Peskind ER, Tsuang D, Wijsman E, Morris JC (1996) Increased risk of dementia in mothers of Alzheimer's disease cases: Evidence for maternal inheritance, Neurology 47, 254-256.

[29] Debette S, Wolf PA, Beiser A, Au R, Himali JJ, Pikula A, Auerbach S, Decarli S, Seshadri S (2009) Association of parental dementia with cognitive and brain MRI measures in middle-aged adults, Neurology 73, 2071-2078.

[30] Scheffler K, Krohn M, Dunkelmann T, Stenzel J, Miroux B, Ibrahim S, von Bohlen Und Halbach O, Heinze HJ, Walker LC, Gsponer JA, Pahnke J (2012) Mitochondrial DNA polymorphisms specifically modify cerebral betaamyloid proteostasis, Acta Neuropathol 124, 199-208.

[31] Parker WD Jr, Filley CM, Parks JK (1990) Cytochrome oxidase deficiency in Alzheimer's disease. Neurology 40, 1302-1303.

[32] Curti D, Rognoni F, Gasparini L, Cattaneo A, Paolillo M, Racchi M, Zani L, Bianchetti A, Trabucchi M, Bergamaschi S, Govoni S (1997) Oxidative metabolism in cultured fibroblasts derived from sporadic Alzheimer's disease (AD) patients. Neurosci Lett 236, 13-16.

[33] Nelson ME, Rejeski WJ, Blair SN, Duncan PW, Judge JO, King AC, Macera CA, Castaneda-Sceppa C (2007) Physical activity and public health in older adults: Recommendation from the American College of Sports Medicine and the American Heart Association. Med Sci Sports Exerc 39, 1435-1445.

[34] Lakka TA, Laukkanen JA, Rauramaa R, Salonen R, Lakka HM, Kaplan GA, Salonen JT (2001) Cardiorespiratory fitness and the progression of carotid atherosclerosis in middle-aged men. Ann Intern Med 134, 12-20.

[35] Houmard JA, Tyndall GL, Midyette JB, Hickey MS, Dolan PL, Gavigan KE, Weidner ML, Dohm GL (1996) Effect of reduced training and training cessation on insulin action and muscle GLUT-4. J Appl Physiol 81, 1162-1168.

[36] Kirwan JP, Kohrt WM, Wojta DM, Bourey RE, Holloszy JO (1993) Endurance exercise training reduces glucosestimulated insulin levels in 60- to 70-year-old men and women. J Gerontol 48, M84-M90.

[37] Cox JH, Cortright RN, Dohm GL, Houmard JA (1999) Effect of aging on response to exercise training in humans: Skeletal muscle GLUT-4 and insulin sensitivity. $J$ Appl Physiol 86, 2019-2025.

[38] Scarmeas N, Luchsinger JA, Schupf N, Brickman AM, Cosentino S, Tang MX, Stern Y (2009) Physical activity, diet, and risk of Alzheimer disease. JAMA 302, 627-637.

[39] van Praag H, Christie BR, Sejnowski TJ, Gage FH (1999) Running enhances neurogenesis, learning, and long term potentiation in mice. Proc Natl Acad Sci U S A 96, 1342713431.

[40] Colcombe S, Kramer AF (2003) Fitness effects on the cognitive function of older adults: A meta-analytic study. Psychol Sci 14, 125-130.

[41] Liu-Ambrose T, Nagamatsu LS, Graf P, Beattie BL, Ashe MC, Handy TC (2010) Resistance training and executive functions: A 12-month randomized controlled trial. Arch Intern Med 170, 170-178.

[42] Burns JM, Cronk BB, Anderson HS, Donnelly JE, Thomas GP, Harsha A, Brooks WM, Swerdlow RH (2008) Cardiorespiratory fitness and brain atrophy in early Alzheimer disease. Neurology 71, 210-216.
[43] Erickson KI, Voss MW, Prakash RS, Basak C, Szabo A, Chaddock L, Kim JS, Heo S, Alves H, White SM, Wojcicki TR, Mailey E, Vieira VJ, Martin SA, Pence BD, Woods JA, McAuley E, Kramer AF (2011) Exercise training increases size of hippocampus and improves memory. Proc Natl Acad Sci U S A 108, 3017-3022.

[44] Honea RA, Thomas GP, Harsha A, Anderson HS, Donnelly JE, Brooks WM, Burns JM (2009) Cardiorespiratory fitness and preserved medial temporal lobe volume in Alzheimer disease. Alzheimer Dis Assoc Disord 23, 188197.

[45] Vidoni ED, Honea RA, Billinger SA, Swerdlow RH, Burns JM (2012) Cardiorespiratory fitness is associated with atrophy in Alzheimer's and aging over 2 years. Neurobiol Aging 33, 1624-1632.

[46] Morris JK, Vidoni ED, Honea RA, Burns JM (2014) Impaired glycemia and Alzheimer's disease. Neurobiol Aging 35, e23.

[47] Sandhir R, Gupta S (2015) Molecular and biochemical trajectories from diabetes to Alzheimer's disease: A critical appraisal. World J Diabetes 6, 1223-1242.

[48] Leung R, Proitsi P, Simmons A, Lunnon K, Güntert A, Kronenberg D, Pritchard M, Tsolaki M, Mecocci P, Kloszewska I, Vellas B, Soininen H, Wahlund LO, Lovestone $S$ (2013) Inflammatory proteins in plasma are associated with severity of Alzheimer's disease. PLoS One 8, e64971.

[49] Mews P, Donahue G, Drake AM, Luczak V, Abel T, Berger SL (2017) Acetyl-CoA synthetase regulates histone acetylation and hippocampal memory. Nature 15, 381-386.

[50] Ren R, Ocampo A, Liu GH, Izpisua Belmonte JC (2017) Regulation of stem cell aging by metabolism and epigenetics. Cell Metab 5, 460-474.

[51] Peleg S, Feller C, Ladurner AG, Imhof A (2016) The metabolic impact on histone acetylation and transcription in ageing. Trends Biochem Sci 41, 700-711.

[52] Arkus N (2005) A mathematical model of cellular apoptosis and senescence through the dynamics of telomere loss. $J$ Theor Biol 235, 13-32.

[53] Cho SG, Choi EJ (2002) Apoptotic signaling pathways: Caspases and stress-activated protein kinases. J Biochem Mol Biol 35, 24-27.

[54] Mecocci P, MacGarvey U, Kaufman AE, Koontz D, Shoffner JM, Wallace DC, Beal MF (1993) Oxidative damage to mitochondrial DNA shows marked age-dependent increases in human brain. Ann Neurol 34, 609-616.

[55] Mecocci P, MacGarvey U, Beal MF (1994) Oxidative damage to mitochondrial DNA is increased in Alzheimer's disease. Ann Neurol 36, 747-751.

[56] Lezza AM, Mecocci P, Cormio A, Beal MF, Cherubini A, Cantatore P, Senin U, Gadaleta MN (1999) Mitochondrial DNA 4977 bp deletion and OH8dG levels correlate in the brain of aged subjects but not Alzheimer's disease patients. FASEB J 13, 1083-1088.

[57] Mecocci P, Cherubini A, Beal MF, Cecchetti R, Chionne F, Polidori MC, Romano G, Senin U (1996) Altered mitochondrial membrane fluidity in AD brain. Neurosci Lett 207, 129-132.

[58] Mecocci P, Beal MF, Cecchetti R, Polidori MC, Cherubini A, Chionne F, Avellini L, Romano G, Senin U (1997) Mitochondrial membrane fluidity and oxidative damage to mitochondrial DNA in aged and AD human brain. Mol Chem Neuropathol 31, 53-64.

[59] Polidori MC, Mecocci P, Browne SE, Senin U, Beal MF (1999) Oxidative damage to mitochondrial DNA in 
Huntington's disease parietal cortex. Neurosci Lett 272, 53-56.

[60] Morris JK, Honea RA, Vidoni ED, Swerdlow RH, Burns JM (2014) Is Alzheimer's disease a systemic disease? Biochim Biophys Acta 1842, 1340-1349.

[61] Mecocci P, Polidori MC, Ingegni T, Cherubini A, Chionne F, Cecchetti R, Senin U (1998) Oxidative damage to DNA in lymphocytes from AD patients. Neurology 51, 10141017.

[62] Mecocci P, Polidori MC, Cherubini A, Ingegni T, Mattioli P, Catani M, Rinaldi P, Cecchetti R, Stahl W, Senin U, Beal MF (2002) Lymphocyte oxidative DNA damage and plasma antioxidants in Alzheimer disease. Arch Neurol 59, 794-798.

[63] Sultana R, Mecocci P, Mangialasche F, Cecchetti R, Baglioni M, Butterfield DA (2011) Increased protein and lipid oxidative damage in mitochondria isolated from lymphocytes from patients with Alzheimer's disease: Insights into the role of oxidative stress in Alzheimer's disease and initial investigations into a potential biomarker for this dementing disorder. $J$ Alzheimers Dis 24, 77-84.

[64] Sultana R, Baglioni M, Cecchetti R, Cai J, Klein JB, Bastiani P, Ruggiero C, Mecocci P, Butterfield DA (2013) Lymphocyte mitochondria: Toward identification of peripheral biomarkers in the progression of Alzheimer disease. Free Radic Biol Med 65, 595-606.

[65] Mangialasche F, Baglioni M, Cecchetti R, Kivipelto M, Ruggiero C, Piobbico D, Kussmaul L, Monastero R, Brancorsini S, Mecocci P (2015) Lymphocytic mitochondrial aconitase activity is reduced in Alzheimer's disease and mild cognitive impairment. J Alzheimers Dis 44, 649-660.

[66] Polidori MC, Mattioli P, Aldred S, Cecchetti R, Stahl W, Griffiths H, Senin U, Sies H, Mecocci P (2004) Plasma antioxidant status, immunoglobulin-G oxidation and lipid peroxidation in demented patients: Relevance to Alzheimer disease and vascular dementia. Dement Geriatr Cogn Disord 18, 265-270.

[67] Mariani E, Polidori MC, Cherubini A, Mecocci P (2005) Oxidative stress in brain aging, neurodegenerative and vascular diseases: An overview. J Chromatogr B Analyt Technol Biomed Life Sci 827, 65-75.

[68] Polidori MC, Griffiths HR, Mariani E, Mecocci P (2007) Hallmarks of protein oxidative damage in neurodegenerative diseases: Focus on Alzheimer's disease. Amino Acids 32, 553-559.

[69] Mangialasche F, Polidori MC, Monastero R, Ercolani S, Camarda C, Cecchetti R, Mecocci P (2009) Biomarkers of oxidative and nitrosative damage in Alzheimer's disease and mild cognitive impairment. Ageing Res Rev 8, 285305.

[70] Mecocci P, Fanó G, Fulle S, MacGarvey U, Shinobu L, Polidori MC, Cherubini A, Vecchiet J, Senin U, Beal MF (1999) Age-dependent increases in oxidative damage to DNA, lipids, and proteins in human skeletal muscle. Free Radic Biol Med 26, 303-308.

[71] Fanò G, Mecocci P, Vecchiet J, Belia S, Fulle S, Polidori MC, Felzani G, Senin U, Vecchiet L, Beal MF (2001) Age and sex influence on oxidative damage and functional status in human skeletal muscle. J Muscle Res Cell Motil 22, 345-351.

[72] Fulle S, Mecocci P, Fanó G, Vecchiet I, Vecchini A, Racciotti D, Cherubini A, Pizzigallo E, Vecchiet L, Senin U, Beal MF (2000) Specific oxidative alterations in vastus lateralis muscle of patients with the diagnosis of chronic fatigue syndrome. Free Radic Biol Med 29, 1252-1259.

[73] Maggio D, Barabani M, Pierandrei M, Polidori MC, Catani M, Mecocci P, Senin U, Pacifici R, Cherubini A (2003) Marked decrease in plasma antioxidants in aged osteoporotic women: Results of a cross-sectional study. J Clin Endocrinol Metab 88, 1523-1527.

[74] Cherubini A, Ruggiero C, Polidori MC, Mecocci P (2005) Potential markers of oxidative stress in stroke. Free Radic Biol Med 39, 841-852.

[75] Polidori MC, Frei B, Cherubini A, Nelles G, Rordorf G, Keaney JF Jr, Schwamm L, Mecocci P, Koroshetz WJ, Beal MF (1998) Increased plasma levels of lipid hydroperoxides in patients with ischemic stroke. Free Radic Biol Med 25, 561-567.

[76] Cherubini A, Polidori MC, Bregnocchi M, Pezzuto S, Cecchetti R, Ingegni T, di Iorio A, Senin U, Mecocci P (2000) Antioxidant profile and early outcome in stroke patients. Stroke 31, 2295-2300.

[77] Polidori MC, Cherubini A, Stahl W, Senin U, Sies H, Mecocci P (2002) Plasma carotenoid and malondialdehyde levels in ischemic stroke patients: Relationship to early outcome. Free Radic Res 36, 265-268.

[78] Polidori MC, Mecocci P, Frei B (2001) Plasma vitamin $\mathrm{C}$ levels are decreased and correlated with brain damage in patients with intracranial hemorrhage or head trauma. Stroke 32, 898-902.

[79] Polidori MC, Cherubini A, Senin U, Mecocci P (2001) Hyperhomocysteinemia and oxidative stress in ischemic stroke. Stroke 32, 275-278.

[80] Polidori MC, Praticó D, Ingegni T, Mariani E, Spazzafumo L, Del Sindaco P, Cecchetti R, Yao Y, Ricci S, Cherubini A, Stahl W, Sies H, Senin U, Mecocci P; AVASAS Study Group (2005) Effects of vitamin C and aspirin in ischemic stroke-related lipid peroxidation: Results of the AVASAS (Aspirin Versus Ascorbic acid plus Aspirin in Stroke) Study. Biofactors 24, 265-274.

[81] Polidori MC, Mecocci P, Stahl W, Parente B, Cecchetti R, Cherubini A, Cao P, Sies H, Senin U (2000) Plasma levels of lipophilic antioxidants in very old patients with type 2 diabetes. Diabetes Metab Res Rev 16, 15-19.

[82] Polidori MC, Praticó D, Parente B, Mariani E, Cecchetti R, Yao Y, Sies H, Cao P, Mecocci P, Stahl W (2006) Elevated lipid peroxidation biomarkers and low antioxidant status in atherosclerotic patients with increased carotid or iliofemoral intima-media thickness. J Investig Med 55, 163-167.

[83] Polidori MC, Ruggiero C, Croce MF, Raichi T, Mangialasche F, Cecchetti R, Pelini L, Paolacci L, Ercolani S, Mecocci P (2015) Association of increased carotid intimamedia thickness and lower plasma levels of vitamin $\mathrm{C}$ and vitamin E in old age subjects: Implications for Alzheimer's disease. J Neural Transm 122, 523-530.

[84] Polidori MC, Praticó D, Savino K, Rokach J, Stahl W, Mecocci P (2004) Increased F2 isoprostane plasma levels in patients with congestive heart failure are correlated with antioxidant status and disease severity. J Card Fail 10, 334-338.

[85] Polidori MC, Mariani E, Mecocci P, Nelles G (2006) Congestive heart failure and Alzheimer's disease. Neurol Res 28, 588-594.

[86] Polidori MC, Marvardi M, Cherubini A, Senin U, Mecocci P (2001) Heart disease and vascular risk factors in the cognitively impaired elderly: Implications for Alzheimer's dementia. Aging (Milano) 13, 231-239. 
[87] Polidori MC, Cherubini A, Senin U, Mecocci P (2001) Peripheral non-enzymatic antioxidant changes with human aging: A selective status report. Biogerontology 2, 99-104.

[88] Polidori MC, Pientka L, Mecocci P (2012) A review of the major vascular risk factors related to Alzheimer's disease. J Alzheimers Dis 32, 521-530.

[89] Polidori MC, Mecocci P (2002) Plasma susceptibility to free radical-induced antioxidant consumption and lipid peroxidation is increased in very old subjects with Alzheimer disease. J Alzheimers Dis 4, 517-522.

[90] Mecocci P, Polidori MC, Troiano L, Cherubini A, Cecchetti R, Pini G, Straatman M, Monti D, Stahl W, Sies H, Franceschi C, Senin U (2000) Plasma antioxidants and longevity: A study on healthy centenarians. Free Radic Biol Med 28, 1243-1248.

[91] Polidori MC, Mariani E, Baggio G, Deiana L, Carru C, Pes GM, Cecchetti R, Franceschi C, Senin U, Mecocci P (2007) Different antioxidant profiles in Italian centenarians: The Sardinian peculiarity. Eur J Clin Nutr 61, 922-924.

[92] Passarino G, Calignano C, Vallone A, Franceschi C, Jeune B, Robine JM, Yashin AI, Cavalli Sforza LL, De Benedictis G (2002) Male/female ratio in centenarians: A possible role played by population genetic structure. Exp Gerontol 37, 1283-1289.

[93] Anlasik T, Sies H, Griffiths HR, Mecocci P, Stahl W, Polidori MC (2005) Dietary habits are major determinants of the plasma antioxidant status in healthy elderly subjects. Br J Nutr 94, 639-642.

[94] Polidori MC, Praticó D, Mangialasche F, Mariani E, Aust O, Anlasik T, Mang N, Pientka L, Stahl W, Sies H, Mecocci P, Nelles G (2009) High fruit and vegetable intake is positively correlated with antioxidant status and cognitive performance in healthy subjects. J Alzheimers Dis 17, 921-927.

[95] Rinaldi P, Polidori MC, Metastasio A, Mariani E, Mattioli P, Cherubini A, Catani M, Cecchetti R, Senin U, Mecocci P (2003) Plasma antioxidants are similarly depleted in mild cognitive impairment and in Alzheimer's disease. Neurobiol Aging 24, 915-919.

[96] Kryscio RJ, Abner EL, Caban-Holt A, Lovell M, Goodman P, Darke AK, Yee M, Crowley J, Schmitt FA (2017) Association of antioxidant supplement use and dementia in the prevention of Alzheimer's disease by vitamin $\mathrm{E}$ and selenium trial (PREADViSE). JAMA Neurol 74, 567-573.

[97] Farina N, Llewellyn D, Isaac MG, Tabet N (2017) Vitamin E for Alzheimer' dementia and mild cognitive impairment. Cochrane Database Syst Rev 4, CD002854.

[98] Jiang Q (2014) Natural forms of vitamin E: Metabolism, antioxidant, and anti-inflammatory activities and their role in disease prevention and therapy. Free Radic Biol Med 72, 76-90.

[99] Ravaglia G, Forti P, Maioli F, Martelli M, Servadei L, Brunetti N, Dalmonte E, Bianchin M, Mariani E (2005) Incidence and etiology of dementia in a large elderly Italian population. Neurology 64, 1525-1530.

[100] Ravaglia G, Forti P, Lucicesare A, Pisacane N, Rietti E, Mangialasche F, Cecchetti R, Patterson C, Mecocci P (2008) Plasma tocopherols and risk of cognitive impairment in an elderly Italian cohort. Am J Clin Nutr 87, 1306-1313.

[101] Mangialasche F, Kivipelto M, Mecocci P, Rizzuto D, Palmer K, Winblad B, Fratiglioni L (2010) High plasma levels of vitamin E forms and reduced Alzheimer's disease risk in advanced age. $J$ Alzheimers Dis 20, 10291037.

[102] Mangialasche F, Solomon A, Kåreholt I, Hooshmand B, Cecchetti R, Fratiglioni L, Soininen H, Laatikainen T, Mecocci P, Kivipelto M (2013) Serum levels of vitamin E forms and risk of cognitive impairment in a Finnish cohort of older adults. Exp Gerontol 48, 1428-1435.

[103] Mangialasche F, Xu W, Kivipelto M, Costanzi E, Ercolani S, Pigliautile M, Cecchetti R, Baglioni M, Simmons A, Soininen H, Tsolaki M, Kloszewska I, Vellas B, Lovestone S, Mecocci P; AddNeuroMed Consortium (2012) Tocopherols and tocotrienols plasma levels are associated with cognitive impairment. Neurobiol Aging 33, 2282-2290.

[104] Mangialasche F, Westman E, Kivipelto M, Muehlboeck JS, Cecchetti R, Baglioni M, Tarducci R, Gobbi G, Floridi P, Soininen H, Kloszewska I, Tsolaki M, Vellas B, Spenger C, Lovestone S, Wahlund LO, Simmons A, Mecocci P; AddNeuroMed consortium (2013) Classification and prediction of clinical diagnosis of Alzheimer's disease based on MRI and plasma measures of $\alpha-/ \gamma$-tocotrienols and $\gamma$-tocopherol. J Intern Med 273, 602-621.

[105] Picco A, Polidori MC, Ferrara M, Cecchetti R, Arnaldi D, Baglioni M, Morbelli S, Bastiani P, Bossert I, Fiorucci G, Brugnolo A, Dottorini ME, Nobili F, Mecocci P (2014) Plasma antioxidants and brain glucose metabolism in elderly subjects with cognitive complaints. Eur J Nucl Med Mol Imaging 41, 764-775.

[106] Sano M, Ernesto C, Thomas RG, Klauber MR, Schafer K, Grundman M, Woodbury P, Growdon J, Cotman CW, Pfeiffer E, Schneider LS, Thal LJ (1997) A controlled trial of selegiline, alpha-tocopherol, or both as treatment for Alzheimer's disease. $N$ Engl J Med 336, 12161222.

[107] Boccardi V, Baroni M, Mangialasche F, Mecocci P (2016) Vitamin E family: Role in the pathogenesis and treatment of Alzheimer's disease. Alzheimers Dement (N Y) 2, 182191.

[108] Mariani E, Cornacchiola V, Polidori MC, Mangialasche F, Malavolta M, Cecchetti R, Bastiani P, Baglioni M, Mocchegiani E, Mecocci P (2006) Antioxidant enzyme activities in healthy old subjects: Influence of age, gender and zinc status: Results from the Zincage Project. Biogerontology 7, 391-398.

[109] Mariani E, Mangialasche F, Feliziani FT, Cecchetti R, Malavolta M, Bastiani P, Baglioni M, Dedoussis G, Fulop T, Herbein G, Jajte J, Monti D, Rink L, Mocchegiani E, Mecocci P (2008) Effects of zinc supplementation on antioxidant enzyme activities in healthy old subjects. Exp Gerontol 43, 445-451.

[110] Mecocci P, Tinarelli C, Schulz RJ, Polidori MC (2014) Nutraceuticals in cognitive impairment and Alzheimer's disease. Front Pharmacol 5, 147.

[111] Boccardi V, Esposito A, Rizzo MR, Marfella R, Barbieri M, Paolisso G (2013) Mediterranean diet, telomere maintenance and health status among elderly. PLoS One 8, e62781.

[112] Boccardi V, Paolisso G, Mecocci P (2016) Nutrition and lifestyle in healthy aging: The telomerase challenge. Aging (Albany, NY) 8, 12-15.

[113] Boccardi V, Pelini L, Ercolani S, Ruggiero C, Mecocci P (2015) From cellular senescence to Alzheimer's disease: The role of telomere shortening. Ageing Res Rev 22, 1-8. 
[114] Harish G, Venkateshappa C, Mahadevan A, Pruthi N, Srinivas Bharath MM, Shankar SK (2012) Effect of premortem and postmortem factors on the distribution and preservation of antioxidant activities in the cytosol and synaptosomes of human brains. Biopreserv Biobank 10, 253-265.

[115] Harish G, Venkateshappa C, Mahadevan A, Pruthi N, Bharath MM, Shankar SK (2011) Effect of storage time, postmortem interval, agonal state, and gender on the postmortem preservation of glial fibrillary acidic protein and oxidatively damaged proteins in human brains. Biopreserv Biobank 9, 379-387.
[116] Petersen RC, Thomas RG, Grundman M, Bennett D, Doody R, Ferris S, Galasko D, Jin S, Kaye J, Levey A, Pfeiffer E, Sano M, van Dyck CH, Thal LJ; Alzheimer's Disease Cooperative Study Group (2005) Vitamin E and donepezil for the treatment of mild cognitive impairment. $N$ Engl J Med 352, 2379-2388.

[117] Farina N, Isaac MG, Clark AR, Rusted J, Tabet N (2012) Vitamin E for Alzheimer's dementia and mild cognitive impairment. Cochrane Database Syst Rev 11, CD002854.

[118] Farina N, Llewellyn D, Isaac MGEKN, Tabet N (2017) Vitamin E for Alzheimer's dementia and mild cognitive impairment. Cochrane Database Syst Rev 4, CD002854. 